\title{
Paraumbilical hernia: an accompaniment of obesity
}

\author{
Sittampalam Rajendra, Shathana Paramanathan, Darshika Karunarasan \\ University Surgical Unit, Teaching Hospital, Jaffna, Sri Lanka
}

Keywords: Incisional hernia; inguinal hernia; para umbilical hernia; predisposing factors; prevalence

\begin{abstract}
Introduction

Inguinal hernia, paraumbilical hernia and incisional hernias are common abdominal wall hernias encountered in surgical practice. Smoking, straining during micturition and/or defaecation, heavy manual work, chronic obstructive airway disease and obesity are some of the recognized predisposing factors for abdominal wall hernias in adults.
\end{abstract}

\section{Objective}

The study aims to estimate the prevalence of the common predisposing factors of abdominal hernias among adults of both genders.

\section{Methodology}

This is an institutional-based cross-sectional analytic study carried out in adult patients with abdominal hernias registered at a surgical clinic, Teaching Hospital, Jaffna, from January 2018 to December 2020. Interviewer administered questionnaire was used to collect the data from the patients. Data were analyzed by Statistical Package for Social Sciences version $21.5 \%$ was used as a significance level.

\section{Results}

Among the 218 patients, 119 patients [54.6\%] had an inguinal hernia, 80 [36.7\%] had a paraumbilical hernia and 19 [8.7\%] had an incisional hernia. $36[16.5 \%]$ patients did not have any of the predisposing factors whereas $80[36.7 \%]$ patients had a single predisposing factor and the remaining 102[46.8\%] patients had multiple predisposing factors. 58 [26.6\%] had the habit of smoking. 43 patients [19.8\%] gave a history of straining during defecation and/or micturition and 49 patients [22.5\%] suffered from chronic obstructive airway diseases. 98 patients [45.0\%] were heavy manual workers and 98 [45.0\%] were obese.

\footnotetext{
Correspondence: Sittampalam Rajendra

E-mail: dr.s.rajendra@gmail.com

(i) https://orcid.org/0000-0002-3303-603X
}

Received: 15-08-2021 Accepted: 26-11-2021 DOI: http://doi.org/10.4038/sljs.v39i3.8903

\begin{abstract}
Conclusion
The prevalence of predisposing factors in each type of abdominal wall hernias varies. However, our study reveals, predisposing factors such as smoking, straining during defecation/ micturition, heavy manual work and chronic obstructive airway disease were more common with inguinal hernia while obesity was found more in common with a paraumbilical hernia. Patients with inguinal hernias tend to influence multiple predisposing factors.
\end{abstract}

\section{Introduction}

Protrusion of a viscous or part of a viscous can take place from the peritoneal cavity through the weakened area or defect in the abdominal wall $[1,2]$. These abdominal wall hernias account for about $15-18 \%$ of operative procedures in a surgical unit. Inguinal hernia, incisional hernia and paraumbilical hernia are common types of abdominal wall hernias encountered in surgical practice [3]. There are recognized predisposing factors to abdominal wall hernias. Smoking cigarettes, straining during defecation and micturition, heavy manual work, chronic obstructive airway disease [COPD] and obesity are commonly found predisposing factors among patients with abdominal wall hernias[4].

Obesity is classified based on Body Mass Index. Clinical guidelines by the Endocrine Society of Sri Lanka classified obesity in Sri Lanka as BMI $\geq 25 \mathrm{kgm}^{2}$. The prevalence of obesity in the Sri Lankan population was 9.2\% $[5,6]$. Identifying the prevalence of these predisposing factors among the types of abdominal wall hernias not only help for community health education about the prevention of hernias but is also useful to take measures to prevent recurrent hernias.

\section{Methodology}

This is an institutional-based prospective cross-sectional analytic study carried out in adult patients with abdominal hernias registered at a surgical clinic from January 2018 to December 2020, to analyze the prevalence of the selected predisposing factors in commonly encountered abdominal hernias among adults of both genders. 
Adult patients, aged more than 18 years, with inguinal, incisional and paraumbilical hernias were included. Patients with combinations of these hernias, recurrent hernias and other types of abdominal hernias were excluded.

Interviewer administered questionnaire was used to collect data. It contained biographical data of a patient, height [in meter] and weight [in kilogram] of the patient, type of abdominal hernia and the details of existing predisposing factors such as smoking, straining at defaecation or micturition, heavy manual work, and COPD.

Body mass index was calculated by using the standard formula, $\mathrm{BMI}=$ weight $/$ height $^{2}$.

Those patients who were doing strenuous physical work for wages were considered for heavy manual work. Farmers, painters, welders, masons, cleaners and labourers were considered in this category. Those patients carrying out office work were not considered in this category. Teachers, bank staff, clerical servants and management assistants were considered as not performing heavy manual work.

Findings from the questionnaire were entered on an excel spreadsheet. The final analysis of data was carried out using Statistical Package for Social Sciences version 21. Descriptive analysis was conducted for all predisposing factors and each type of abdominal hernias. Fisher's exact test was used to determine the association of independent variables: predisposing factors with dependent variable; types of abdominal wall hernia by using the $5 \%$ significance level.

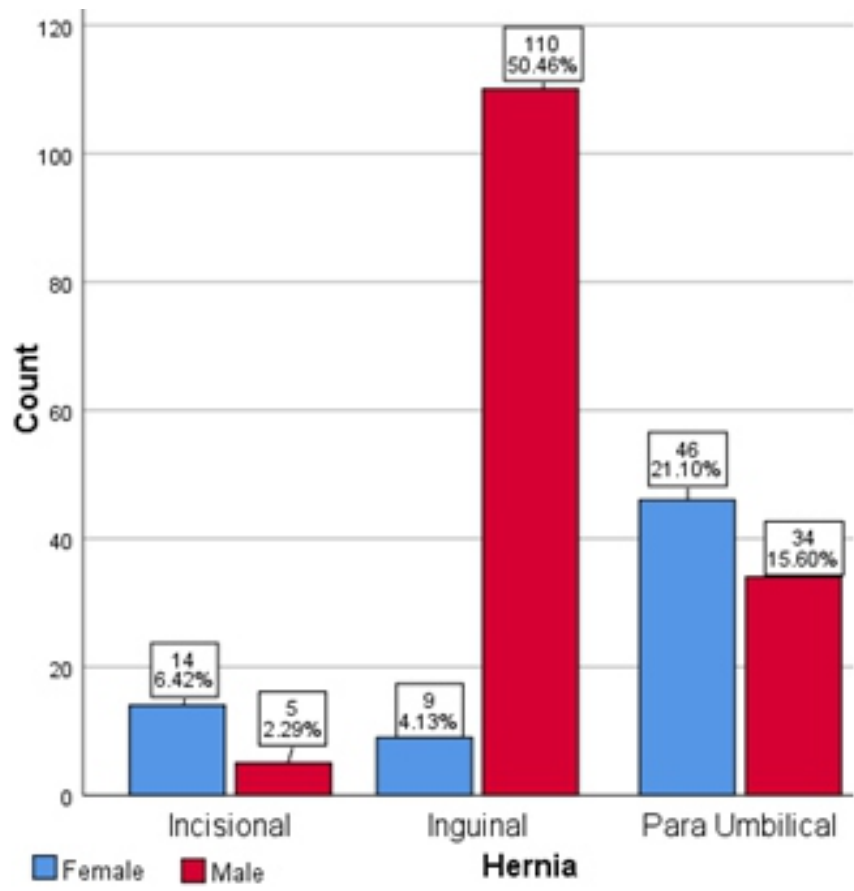

Figure 1. Gender distribution in common types of abdominal wall hernia

\section{Results}

There were 218 patients registered in the Professorial surgical unit with a hernia. 149 [68.3\%] were males and 69 [31.7\%] were females. The mean age was $54.07 \pm 14.59$ years. Among them 119 [54.6\%] had an inguinal hernia, 80 [36.7\%] had a paraumbilical hernia and 19 [8.7\%] had an incisional hernia. Gender distribution in each type of abdominal wall hernia is shown in figure 1 .

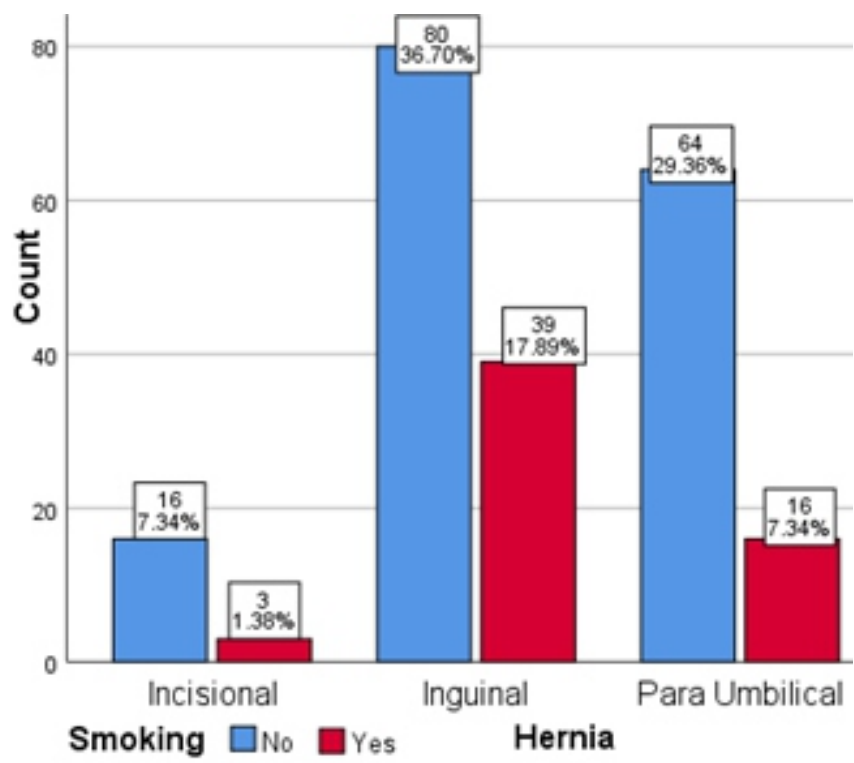

Figure 2. Prevalence of smoking among different types of abdominal hernias

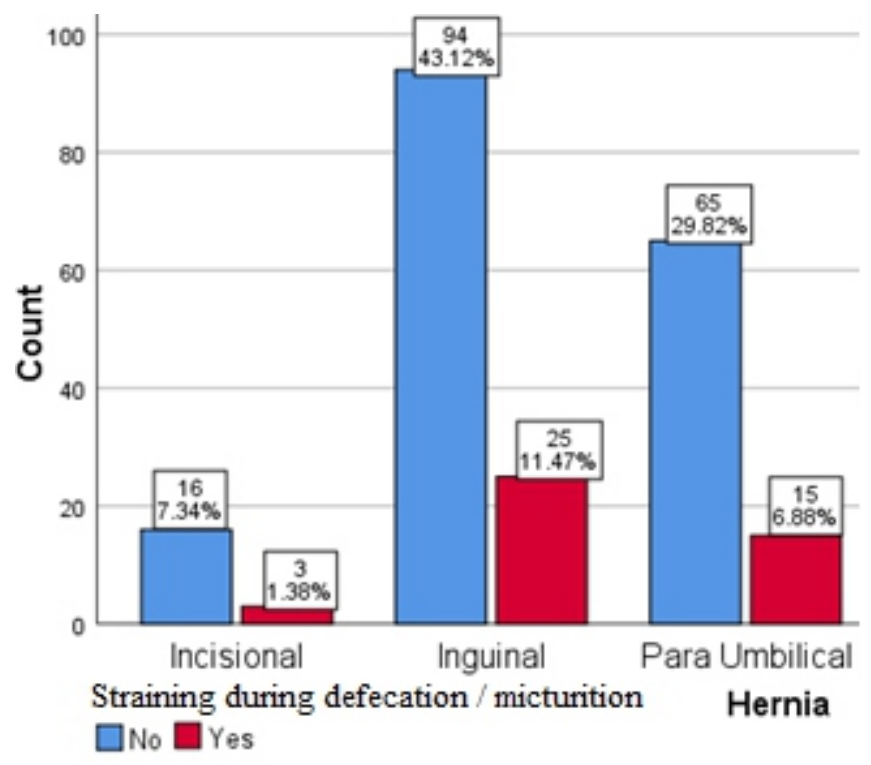

Figure 3. Prevalence of Straining during defecation/ micturition among abdominal hernias 


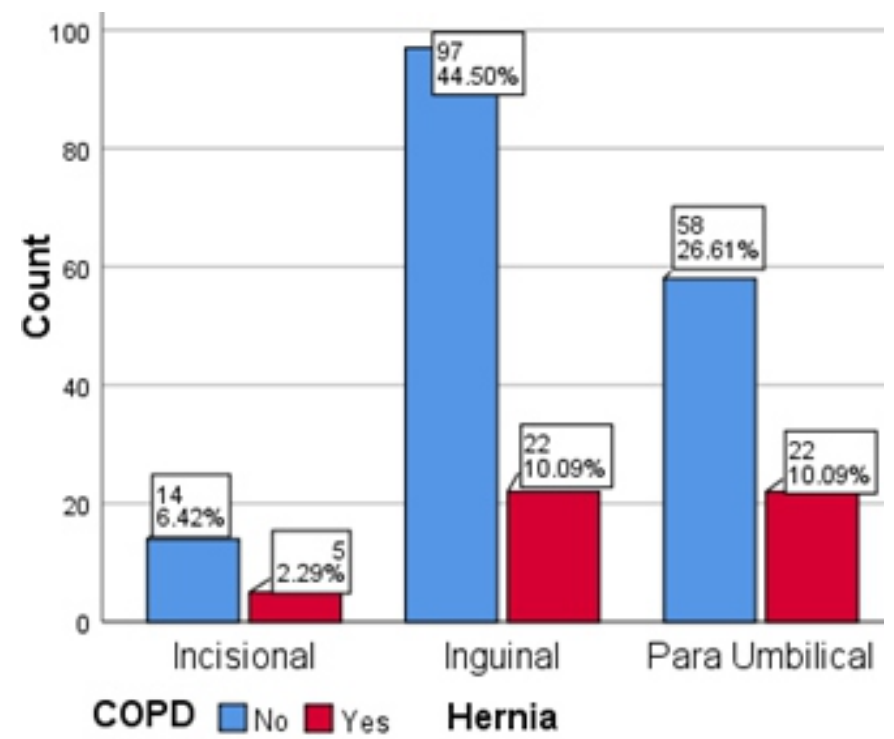

Figure 4. Prevalence of COPD among different types of abdominal hernias

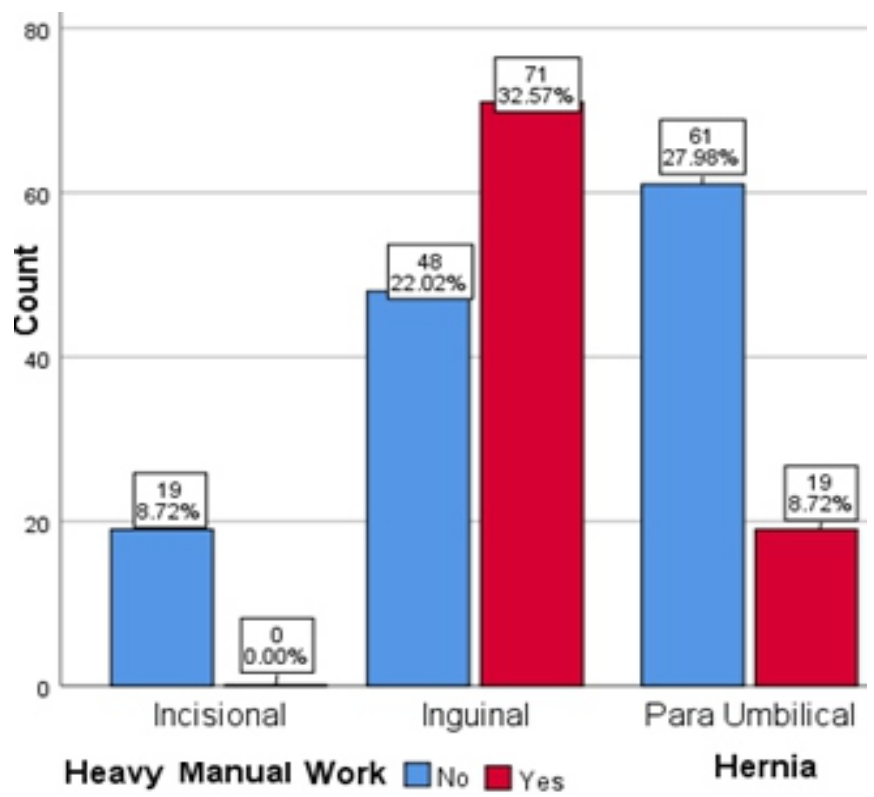

Figure 5. Prevalence of Heavy Manual Work among different types of abdominal hernias

Prevalence of selected predisposing factors in patients with incisional hernia, inguinal hernia and paraumbilical hernia are shown in figures 2-6.

Among the 218 patients with abdominal hernias, 36 [16.5\%] patients did not have any of the predisposing factors. 58 [26.6\%] had the habit of smoking. 43 [19.8\%] patients gave a history of straining for defecation/micturition and 49 patients [22.5\%] were suffering from chronic obstructive airway diseases. 98 patients $[45.0 \%]$ were heavy manual workers and $98[45.0 \%]$ were obese.

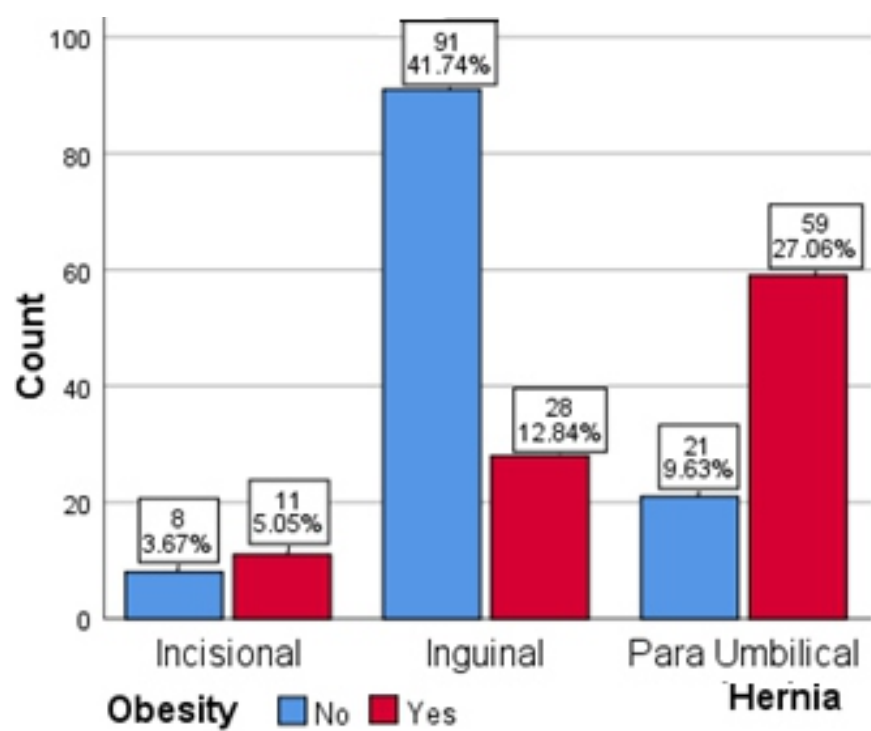

Figure 6. Prevalence of obesity among different types of abdominal hernias

Table 1. Summary of predisposing factor prevalence among different types of abdominal hernias

\begin{tabular}{|l|c|c|c|}
\hline Predisposing factors & $\begin{array}{l}\text { Incisional } \\
\text { Hernia }\end{array}$ & $\begin{array}{l}\text { Inguinal } \\
\text { Hernia }\end{array}$ & $\begin{array}{l}\text { Para Umbilical } \\
\text { Hernia }\end{array}$ \\
\hline Smoking [58] & $\begin{array}{c}3 \\
{[5.17 \%]}\end{array}$ & $\begin{array}{c}39 \\
{[67.24 \%]}\end{array}$ & $\begin{array}{c}16 \\
{[27.59 \%]}\end{array}$ \\
\hline $\begin{array}{l}\text { Straining during defecation/ } \\
\text { micturition [43] }\end{array}$ & 3 & 25 & 15 \\
{$[6.98 \%]$} & {$[58.14 \%]$} & {$[34.88 \%]$} \\
\hline COPD [49] & 5 & 22 & 22 \\
& {$[10.2 \%]$} & {$[44.9 \%]$} & {$[44.9 \%]$} \\
\hline Heavy manual work [90] & 0 & 71 & 19 \\
& {$[0.0 \%]$} & {$[78.89 \%]$} & {$[21.11 \%]$} \\
\hline Obesity [98] & 11 & 28 & 59 \\
& {$[11.2 \%]$} & {$[28.6 \%]$} & {$[60.2 \%]$} \\
\hline
\end{tabular}

Among the patients with a hernia who had a smoking habit most of them [67.2\%] had an inguinal hernia and only a few $[5.2 \%]$ had an incisional hernia which is noticeable in figure 2. Patients who had straining for defecation/micturition rarely [7\%] were found to have incisional hernia while they frequently [58.1\%] had an inguinal hernia, as illustrated in figure 3. COPD patients had an equal chance [44.9\%] of developing inguinal and paraumbilical hernias but only $10.2 \%$ of them had an incisional hernia [Figure 4]. Heavy manual work is one of the important predisposing factors for hernia, which showed a significant difference with the type of abdominal wall hernia in our study [Fisher's exact test, 
Table 2. Combination of predisposing factors among gender and types of abdominal wall hernias

\begin{tabular}{|l|c|c|c|c|c|c|}
\hline $\begin{array}{l}\text { Predisposing } \\
\text { factors }\end{array}$ & $\begin{array}{l}\text { No factors } \\
{[\mathbf{n}=\mathbf{3 6}]}\end{array}$ & $\begin{array}{l}\text { One factor } \\
{[\mathbf{n}=80]}\end{array}$ & $\begin{array}{l}\text { Two factors } \\
{[\mathbf{n = 6 2 ]}}\end{array}$ & $\begin{array}{l}\text { Three factors } \\
{[\mathbf{n}=\mathbf{2 8}]}\end{array}$ & $\begin{array}{l}\text { Four factors } \\
{[\mathbf{n}=\mathbf{1 0}]}\end{array}$ & $\begin{array}{l}\text { All selected } \\
\text { factors [n=2] }\end{array}$ \\
\hline Male & $24[66.7 \%]$ & $44[55 \%]$ & $45[72.6 \%]$ & $25[89.3 \%]$ & $9[90 \%]$ & $2[100 \%]$ \\
\hline Fernale & $12[33.3 \%]$ & $36[45 \%]$ & $17[27.4 \%]$ & $3[10.7 \%]$ & $1[10 \%]$ & $0[0.0 \%]$ \\
\hline Inguinal hernia & $23[63.9 \%]$ & $35[43.3 \%]$ & $38[61.3 \%]$ & $19[67.9 \%]$ & $3[30 \%]$ & $1[50 \%]$ \\
\hline Incisional hernia & $3[8.3 \%]$ & $11[13.8 \%]$ & $4[6.5 \%]$ & $1[3.6 \%]$ & $0[0.0 \%]$ & $0[0.0 \%]$ \\
\hline PUH & $10[27.8 \%]$ & $34[42.5 \%]$ & $20[32.2 \%]$ & $8[28.6 \%]$ & $7[70 \%]$ & $1[50 \%]$ \\
\hline
\end{tabular}

p-value: 0.0001$]$. Considering all the patients who performed heavy manual work, most of them [79\%] had an inguinal hernia, only $21 \%$ of them had a paraumbilical hernia and none of them developed an incisional hernia, as evidenced in Figure 5. The predisposing factor obesity showed a significant difference with the type of abdominal wall hernia [Fisher's exact test, p-value: 0.0001]. Moreover, out of all obese patients with an abdominal hernia, a higher percentage [60.2\%] of them comprised of paraumbilical hernia and only a few [11.2\%] of them comprised of incisional hernia, which is exemplified in Figure 6.

More than one predisposing factor was found in 102 patients $[46.8 \%]$ with abdominal wall hernias. More male than female patients with abdominal wall hernias had more than two predisposing factors. Patients with inguinal hernia had more predisposing factors compared to patients with other types of abdominal wall hernias.

\section{Discussion}

The mean age of this study group with abdominal hernias was $54.07 \pm 14.59$ years. In India, the majority of abdominal hernia patients were found in the 41-50 years age group [7]. The highest incidence of inguinal hernia was found in the 51-60 years age group in Pakistan [3].149 [68.3\%] of abdominal wall hernias were found in males. Many of the males are breadwinners of their families and do heavy manual work. Smoking habit is almost exclusively found in males in our culture. Abdominal strain during micturition, a manifestation of prostomegaly, increases with age. As such males develop abdominal wall hernias more than females $[7,8,4]$.

Considering the prevalence of each of the common types of abdominal wall hernias in the loco-regional countries, the inguinal hernias are the most common type of abdominal hernia, followed by a paraumbilical hernia and incisional hernia [Table 3]. While this overall pattern of prevalence of each hernia type remains the same globally, it is interesting to note that the prevalence of paraumbilical hernia [35.7\%] in this study [in Jaffna] is slightly higher when compared to its
Table 3. Prevalence of common abdominal hernia types in different

\begin{tabular}{|l|c|c|c|c|c|}
\hline Type of hernia & India & Pakistan & UK & USA & $\begin{array}{c}\text { Jaffna } \\
\text { [Sri Lanka] }\end{array}$ \\
\hline Inguinal & $77.81 \%$ & $76.35 \%$ & $82.05 \%$ & $88 \%$ & $54.6 \%$ \\
\hline Paraumbilical & $9.06 \%$ & $12.38 \%$ & $3 \%$ & $2 \%$ & $36.7 \%$ \\
\hline Incisional & $3.12 \%$ & $2.7 \%$ & $6.50 \%$ & $10 \%$ & $8.7 \%$ \\
\hline
\end{tabular}

prevalence in other studies.

Considering gender distribution of abdominal wall hernias, inguinal hernias had a male: female ratio of 12.2:1 whereas paraumbilical hernia had a male: female ratio of $1: 1.3$ in this study [Figure 1]. A similar kind of gender distribution has been reported in studies from Pakistan and India [3, 8].

Smoking increases the risk of developing hernias fourfold [9]. Smoking reduces collagen synthesis, decreases the ratio of type I to type III collagen and it also increases the connective tissue degradation by reducing the inhibitor activity of antiprotease activity [10]. Smoking was a predisposing factor for 58 [26.6\%] patients with abdominal wall hernias among them 39 patients presented with inguinal hernia. Sorensen LT et al demonstrated the association of smoking with inguinal hernia recurrence [11].

Straining during defecation and micturition, COPD and heavy manual work, cause increased intra-abdominal pressure. The increased intra-abdominal pressure can bring about secondary changes in tissue fibroblast. Thus the increased intra-abdominal pressure produces areas of weakness in the anterior abdominal wall resulting in abdominal wall hernias [10].

Predisposing factors causing increased intra-abdominal pressure had varying degrees of impact over the common types of abdominal wall hernias. Heavy manual work was found to have a significant difference with abdominal wall hernias $[p=0.0001]$ in this study. Many patients registering themselves in hospital surgical clinics are from a low socio- 
economic background. They have increased physical activities during their work resulting in increased intraabdominal pressure. Vijayakumar S et al described a higher incidence of bilateral inguinal hernia among patients with chronic cough and heavy weight lifting [7]

Increased intra-abdominal fat deposition in obesity causes increased intra abdominal pressure and exerts tension on the midline aponeurosis. The weight of excess fat deposited in the subcutaneous tissue in obesity exerts downward traction on the aponeurosis above the umbilicus. This changes the pattern of decussation of fibres around the umbilicus. The weakened area thus produced allows the appearance of a paraumbilical hernia $[12,13]$.

Ninety eight [45.0\%] patients with abdominal wall hernia were obese. Obesity was found to have a significant difference with abdominal wall hernias $[\mathrm{p}=0.0001]$ in this study. Out of 98 obese patients, 59 patients had an accompanying paraumbilical hernia. Ali $\mathrm{S}$ et al reported increased BMI as a significant predisposing factor for paraumbilical hernia [14]. Lau B et al pointed out the increased risk of incarceration of non-inguinal abdominal wall hernias with increasing BMI of patients [15]. The risk of hernia recurrence and postoperative complications are more with obesity [16]. Interestingly, lower incidences of inguinal hernias were reported with increasing BMI [17]. It has been suggested that pre peritoneal and intra abdominal fat can function as a barrier to prevent herniation across the inguinal hernia defects [18].

Pathogenesis of incisional hernia is influenced not only by patient-related factors and by biological factors, but also by surgery-related factors. The surgery-related predisposing factors are emergency surgeries, laparotomy for peritonitis, type of abdominal incisions, a technique used to close incisions and wound infections [10]. These predisposing factors were not included in this research study, which may be a limitation of this study. When the analysis was considered, the predisposing factors [independent variables] had few or no observations for incisional hernia [dependent variable] in this study. So, Fisher's exact test was used instead of the Chisquare test as reported in the literature for the method of analysis, [19].

Inguinal hernia is potentially protected by obesity to become clinically visible. So, an inguinal hernia is not a frequent accompaniment of obesity. On the other hand the results of our study as well as from findings of studies in literature, it seems obvious that paraumbilical hernia is a frequent accompaniment of obesity. Furthermore, it should also be noted that nearly half of the patients with abdominal wall hernias are influenced by more than one predisposing factor.
So, an active search for possible predisposing factors in patients with abdominal wall hernia is important for their optimal management.

\section{Conclusion}

The prevalence of predisposing factors in each type of abdominal wall hernias varies. However, our study revealed that predisposing factors such as smoking, straining during defecation/ micturition, heavy manual work and chronic obstructive airway disease were more common with inguinal hernia while obesity was found more in association with a paraumbilical hernia. Patients with inguinal hernias tend to be associated with multiple predisposing factors.

All authors disclose no conflict of interest. The study was conducted in accordance with the ethical standards of the relevant institutional or national ethics committee and the Helsinki Declaration of 1975, as revised in 2000 .

\section{References}

1. Sultan B, Quresh Z, Malik MA. Frequency of external hernias in Ayub teaching hospital Abbottabad. Journal of Ayub Medical College Abbottabad. 2009 Sep 1;21[3]:57-8.

2. Maia R, Salgaonkar H, Lomanto D, Shabbir A. Ventral hernia and obesity: is there a consensus. Ann Laparosc Endosc Surg. 2019 Feb; $4: 17$.

https://doi.org/10.21037/ales.2019.01.07

3. Iqbal MN, Akhter S, Irfan M. Prevalence of hernia in relation to various risk factors in Narowal, Pakistan. Sci Lett. 2015;3[1]:2932.

4. Balamaddaiah G, Reddy SR. Prevalence and risk factors of inguinal hernia: a study in a semi-urban area in Rayalaseema, Andhra Pradesh, India. International Surgery Journal. 2016 Dec 9;3[3]:1310-3.

https://doi.org/10.18203/2349-2902.isj20162208

5. Somasundaram N, Rajaratnam H, Wijeyarathne C, Katulanda P, De Silva S, Wickramasinghe P. Clinical guidelines: The Endocrine Society of Sri Lanka; Management of obesity. Sri Lanka J Diabetes. 2014;4:55-70.

https://doi.org/10.4038/sjdem.v4i1.7260

6. Katulanda P, Jayawardena MA, Sheriff MH, Constantine GR, Matthews DR. Prevalence of overweight and obesity in Sri Lankan adults. Obesity reviews. 2010 Nov;11[11]:751-6. https://doi.org/10.1111/j.1467-789X.2010.00746.x

7. Vijayakumar MS, Alagar R. A study on incidence and risk factors of inguinal hernia in ESI population. IOSR J Dent Med Sci. 2003;15[7]:2279-861.

8. Sangwan M, Sangwan V, Garg M, Mahendirutta P, Garg U. Abdominal wall hernia in a rural population in India-Is spectrum changing? Open journal of epidemiology. 2013 Jul 29; 2013. https://doi.org/10.4236/ojepi.2013.33020

9. Sorensen LT, Hemmingsen UB, Kirkeby LT, Kallehave F, Jorgensen LN. Smoking is a risk factor for incisional hernia. Arch surg 2005; 140:119-123.

https://doi.org/10.1001/archsurg.140.2.119 
10.Mutwali I. Incisional hernia: Risk factors, incidence, pathogenesis, prevention and complications. Sudan Med. Monit. 2014Apr 1;9:81. https://doi.org/10.4103/1858-5000.146580

11.Sorensen LT, Friis E, Jorgensen T, Vennits B, Andersen BR, Rasmussen GI, Kjaergaard J. Smoking is a risk factor for recurrence of groin hernia. World journal of surgery. $2002 \mathrm{Apr}$; 26[4]:397-400. https://doi.org/10.1007/s00268-001-0238-6

12. Askar OM. A new concept of the aetiology and surgical repair of paraumbilical and epigastric hernias. Annals of the Royal College of Surgeons of England. $1978 \mathrm{Jan} ; 60[1]: 42$.

13.Sugerman HJ. Hernia and obesity. In Abdominal wall hernias 2001 [pp. 672-674]. Springer, New York, NY. https://doi.org/10.1007/978-1-4419-8574-3 102

14.Ali S, Mujahid MD, Javed A, Hussain MZ. Incidence of Paraumbilical Hernia in Patients with Increased BMI. Annals of Punjab Medical College [APMC]. 2018; 12[4].

15. Lau B, Kim H, Haigh PI, Tejirian T. Obesity increases the odds of acquiring and incarcerating noninguinal abdominal wall hernias. The American Surgeon. 2012 Oct; 78[10]:1118-21. https://doi.org/10.1177/000313481207801024
16.Menzo EL, Hinojosa M, Carbonell A, Krpata D, Carter J, Rogers AM. American Society for Metabolic and Bariatric Surgery and American Hernia Society consensus guideline on bariatric surgery and hernia surgery. Surgery for Obesity and Related Diseases. 2018 Sep 1; 14[9]:1221-32. https://doi.org/10.1016/j.soard.2018.07.005

17.Ruhl CE, Everhart JE. Risk factors for inguinal hernia among adults in the US population. American journal of epidemiology. 2007 May 15; 165[10]:1154-61. https://doi.org/10.1093/aje/kwm011

18.Zendejas B, Hernandez-Irizarry R, Ramirez T, Lohse CM, Grossardt BR, Farley DR. Relationship between body mass index and the incidence of inguinal hernia repairs: a population-based study in Olmsted County, MN. Hernia. 2014 Apr; 18[2]:283-8. https://doi.org/10.1007/s10029-013-1185-5

19.Namuth-Covert DM, Merk HL, Haines C. Chi-Square Test for Goodness of Fit in a Plant Breeding Example. Journal of Natural Resources and Life Sciences Education. 2012;41[1]: p-14. https://doi.org/10.4195/jnrlse.2011.0014w 